\title{
Initial effects of the COVID-19 pandemic on Ecuadorian Healthcare Providers' self-reported anxiety
}

\author{
Gabriella Gaus Hinojosa [1]. \\ 1. University of Wisconsin-Madison - Estados Unidos \\ Doi: $\underline{\text { https://doi.org/10.23936/pfr.v6i2.201 }}$
}

PRÁCTICA FAMILIAR RURAL | Vol.6 | No.2 | Julio 2021 | Recibido: 29/05/2021 | Aprobado: 29/07/2021

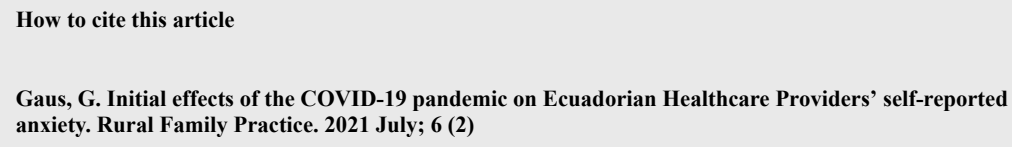

Compartir en:

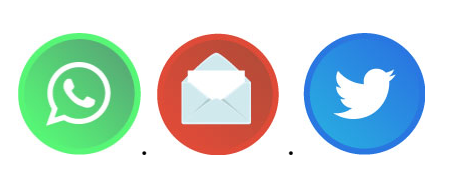

\begin{abstract}
During the early stages of the COVID-19 pandemic Ecuador was one of the countries most impacted globally. Major instances of corruption, widespread COVID-19 fatalities and cases, and a strained health care system impacted Ecuadorian healthcare providers' occupational responsibilities and environment. Research on the psychological consequences of the COVID-19 pandemic on Ecuadorian healthcare providers is. The aim of this study is to evaluate the psychological impact of the COVID-19 Pandemic on Ecuadorian health care providers' anxiety. A nation-wide (nationwide) survey of 293 physicians, nurses, and health care workers in Ecuador was conducted to understand their self-reported anxiety as measured by the Zung selfreported anxiety scale. The mean score $(\mathrm{M}=39.14, S D=8.17)$ on the Zung was just under the clinical anxiety threshold. Additionally, a majority $(63 \%, n=114)$ of the sample met the clinical threshold for anxiety, highlighting the high psychological toll on health care workers during the COVID pandemic. Explanatory factors and future policy and research recommendations are discussed.
\end{abstract}

Key words: mental health, anxiety, health providers, mental exhaustion.

Efectos iniciales de la pandemia de COVID-19 en la ansiedad autoinformada por los proveedores de servicios de salud ecuatorianos

\section{Resumen}

Durante las primeras etapas de la pandemia de COVID-19, Ecuador fue uno de los países más afectados a nivel mundial. La corrupción, las muertes y casos generalizados de COVID-19 en un sistema de atención de salud tenso, afectaron las responsabilidades y medio ambiente laboral de los proveedores de atención médica. El objetivo de este estudio es evaluar el impacto psicológico de la pandemia COVID-19 en la ansiedad de los proveedores de servicios de salud ecuatorianos. Se realizó una encuesta a nivel nacional (a nivel nacional) de 293 médicos, enfermeras y trabajadores de la salud en Ecuador para comprender su ansiedad autoinformada según lo medido por la escala de ansiedad autoinformada de Zung. La puntuación media $(\mathrm{M}=39,14, \mathrm{SD}=8,17)$ en el Zung estaba justo por debajo del umbral de ansiedad clínica. Además, la mayoría $(63 \%, \mathrm{n}=114)$ de la muestra alcanzó el umbral clínico de ansiedad, destacando el alto costo 
psicológico para los trabajadores de la salud durante la pandemia de COVID. Se discuten los factores explicativos y las recomendaciones de investigación y políticas futuras.

Palabras clave: salud mental, ansiedad, proveedores de salud, agotamiento mental.

\section{Introducción}

On March 11th, 2020 the World Health Organization declared the coronavirus disease COVID-19 a global pandemic (World Health Organization 2020). Ecuador's first COVID-19 case was reported in Guayaquil on February 29th and within the first weeks of April, the city's overall death toll from all causes was 6 times greater than previous years (Chiriboga et al., 2020). With more than 1,000 deaths per 1 million habitants as of September 2020, Ecuador was one of the countries most impacted globally during the early stages of the pandemic (Herrera et al., 2021). Many factors challenged the Ecuadorian healthcare system, including severely limited personal protective equipment, limited COVID-19 tests, and a scarcity of intensive care units (Herrera et al. 2020). Because the average reverse transcription polymerase chain reaction (RT-PCR) diagnostic test initially cost $\$ 120$, and the Ecuadorian minimum wage is \$400 a month, many individuals instead relied on more affordable antibody tests of questionable reliability (Herrera et al. 2020). Additionally, data from April 2021 reported Ecuador's 17 million inhabitants relied on 398 intensive care units and 1,183 intensive care beds ( 2 and 7 beds per 100,000 inhabitants, respectively) (Navarro et al., 2020). As Herrera reports, high instances of corruption, lack of transparency, and lack of trust towards the government have also had serious consequences for providers trying to fulfill occupational responsibilities under crisis conditions (Herrera et al. 2020).

Evidence indicates the pandemic has negatively impacted the working conditions of healthcare professionals. The early COVID-19 outbreak in Guayaquil included horrible scenes of corpses left abandoned on streets and an new outlets reporting an estimated $40 \%$ of healthcare workers were infected with COVID (El Comercio 2020). As of July 2020, Ecuador was one of the countries with the highest number of fatalities of healthcare professionals (Amnesty International 2020). Additionally, to this day what day? over 100 families don't know where the bodies of their loved ones are after being admitted during this outbreak in Guayaquil (Medina, Morán, Ponce 2021). The conditions in Guayaquil caused many to fear there would be higher COVID concentrations in hospitals or that if they died in hospitals, they wouldn't be able to have adequate funerals- both worsening the revictimization of health care workers (Herrera et al. 2020). The Ecuadorian Institute of Social Security (IESS) reported that as of June 2020 at least 2,000 healthcare workers quit due to pandemic related risks, working conditions, and concerns over feeling unprotected (France 24, 2020).

Data suggest that COVID-19 related stress and poor working conditions have resulted in greater psychological distress amongst healthcare professionals (Marvaldi et al., 2021; Navarro et al. 2020). In some Ecuadorian provinces an alarming level of individuals from the general population were identified with severe or extremely severe depression, anxiety, and stress during the pandemic (Tusev et al., 2020). Healthcare providers are not only in direct contact with sick patients, but also with their pain and suffering, which augments their psychological risk (Álvarez et al., 2021). Ecuadorian physicians and nurses working during the COVID-19 pandemic have reported severe or moderate burnout (Vinueza-Veloz et al., 2020). Although there is limited research of this kind on culturally similar populations (Tusev et al. 2020), international studies indicate concerns about healthcare providers' anxiety, stress, fear, frustration, depression, insomnia, post-traumatic stress, and anger (Marvaldi et al. 2021; Garcia-Iglesias et al. 2020; Spoorthy et al. 2020; Sahebi et al. 2021).

International research has suggested risk and protective factors against the negative psychological impact of pandemics on healthcare workers. For example, health care providers reported varying psychological distress associated with the following risk factors: type of healthcare profession, working in high-risk units, having direct contact with affected patients, and perception of risk due to the pandemic (Preti et al. 2020). Protective factors included personal variables such as resilience indicators and self-efficacy, altruistically accepting the risk of infection, and confidence in equipment and infection control measures, training, and organizational support (Preti et al. 2021). Psychological symptoms such as anxiety can be a normal reaction to stress and have been associated with fuller compliance with government COVID-19 safety regulations (Orellana \& Orellana 202; Paulino et al. 2020 as cited in Santabarbara et al. 2021).

However, excessive anxiety can also lead to mistrust and non-adherence to COVID-19 safety regulations and impact the quality of care of patients (Asmudson and Taylor 2020; Tawfik et al. 2019; Pereira-Lima et al. 2019). Various organizational-level psychological interventions have been proposed to support health care workers (Álvarez et al. 2021), but there is little evidence for how they are being implemented in Ecuador. Historically, Ecuadorian mental health infrastructure includes low rates of psychologists per capita, and relatively high treatment costs (Capella Palacios and Jadhav 2020).

\section{Present study}

The current study evaluated the psychological impact of the COVID-19 Pandemic on Ecuadorian health care providers' anxiety. A nation-wide survey of physicians, nurses, and health care workers in Ecuador was conducted to understand their self-reported anxiety as measured by the Zung self-reported anxiety scale (SAS; Zung 1971). The SAS was designed to allow for comparisons of an individual's results with norm-referenced group of sufferers where scores equal or exceeding a specified cut-off point are considered to indicate the likely presence of anxiety disorders (Dunstan \& Scott 2020; Zung 1971). The SAS been used in previous studies exploring levels of anxiety amongst health care professionals in Ecuador (Lasluisa 2019). The author sought to understand whether 
anxiety levels varied according to demographic, occupational, and structural factors. Regarding demographic factors, given prior research, we hypothesized health care providers who were women, those with more dependents, those with chronic illness, and those in Coastal areas may report greater anxiety levels. Regarding occupational factors we hypothesized nurses and nursing assistants, individuals working in urgent/ emergency care, and those with less workplace experience would report greater anxiety levels. Finally, regarding structural factors, we hypothesized providers with greater resources (those working in the private sector, who received training about the crisis, who had a permanent work contract, and had mental health support in the workplace) would report lower clinical anxiety levels.

\section{Method}

\section{Sample and Selection Criteria}

In March 2020 we sent recruitment emails to approximately 3,000 individuals subscribed as members of Ecuadorian medical associations. The invitation email included a link to a 34-item electronic survey outlining informed consent and instructions. At participants' discretion, participants were encouraged to circulate the link to colleagues via WhatsApp. Data collection was closed in August 2020.

A total of $N=365$ survey responses were collected, $293(80.2 \%)$ of which were completed fully and used for the final analysis. Participants were included if they were: 1) health care workers, 2) working in-person during the COVID-19 pandemic, 3) working in Ecuador. The final sample of $N=293$ participants consisted of $n=158$ physicians $(53.9 \%)$ and $n=108$ nurses and nursing assistants $(36.86 \%)$ and $n=27$ other healthcare professionals $(9.22 \%)$. Respondents were predominantly women $(n=212 ; 72 \%)$ and ranged in age from 23 to $63(M=36 ; S D=8.2)$.

\section{Measures}

Participant characteristics. We surveyed respondents on 14 demographic, occupational, and structural characteristics. We collected demographic information including: gender (male, female), number of dependents (partner, children, partner and children, parents, parents and siblings, parents and partner, all of the above, none of the above), and participant presence of chronic illness (yes, no), and region of employment (Guayas, Manabí, Pichincha, Santo Domingo, Other); occupational information including: profession (Nursing assistant, stretcher-bearer, ambulance driver, nursing, imaging testing radiologist, lab technician, and physician), professional area (Urgency Care, Emergency care, Outpatient, Inpatient), years since graduation (1 to 2 years, 2 to 5 years, 5 to 10 years, more than 10 years); and structural information such as: sector of practice (Ecuadorian Institute of Social Security [IESS], Ecuadorian Ministry of Health [MSP], private sector), receipt of training about the health crisis within the past week (yes, no), employment stability as indicated by a permanent work contract (yes, no), and the presence of mental health support in the workplace (yes, no).

Zung's Self-rating Anxiety Scale (SAS). The SAS is a 20-item, norm-referenced anxiety screener developed in 1971 and extensively used in international research in the disciplines of psychiatry, psychology, and other medical disciplines (Dunstan \& Scott 2017, 2020; Santabárbara et al. 2021). Items assess affective and somatic symptoms of anxiety found in Diagnostic and Statistical Manual of Mental Disorders (DSM-II; American Psychological Association, 1968). Found to perform comparatively to the anxiety subscale of the Depression Anxiety Stress Scale (DASS) and anxiety disorder classifications in the Patient Health Questionnaire (PHQ), the SAS has good psychometric credentials (Dunstan \& Scott 2020). The SAS uses a 4-point Likert scale ( $1=$ none or little of the time; $4=$ most or all of the time), with five of the items reversed prior to scoring. Scores on the SAS range from 20 to 80 , with higher scores indicating greater distress.

\section{Statistical Analyses}

Descriptive statistics were computed for demographic, occupational and structural factors, and SAS scores. Differences in SAS scores for each factor were assessed using multiple regression using conventional decision rules (i.e., $p<.05$ reflects statistically significant differences among group means). We report post-hoc comparisons for differences between conditions when the overall $R 2$ indicates that the factor significantly predicts anxiety levels. Although significance tests are conducted on raw SAS scores, we also report percentages exceeding the recommended SAS cut-off, which indicates the proportion in each group experiencing clinically significant anxiety levels (Dunstan \& Scott 2020).

In addition to single-predictor analyses, we conducted a five-step hierarchical multiple regression analysis to control for possible confounding among the significant predictor variables. In this analysis, significant demographic predictors were entered in the first and second steps; significant occupational predictors were entered in the third and fourth steps, and significant structural predictors were entered in the fifth step, to assess the effect of each factor (change in $R 2$ ), controlling for previously entered predictor variables. We conducted all statistical analyses in R (R Core Team 2021).

\section{Results}

The mean SAS score for participants was $39.14(S D=6.38)$ and $63.68 \%(n=114)$ of participants met the clinical cut-off for anxiety (Dunstan \& Scott 2020). 
Gender Variables were dummy coded with female-identifying individuals as the reference group. Anxiety among female healthcare providers $(\mathrm{t}(291)=4.1495, \mathrm{p}<.01$; Cohen's $d=.52,95 \%$ CI $[0.26,0.78])$ was significantly higher than among men, as seen in Table 1. Among women, $44 \%$ exceeded the clinical threshold for anxiety $(\mathrm{M}=40.07, \mathrm{SD}=6.35)$, compared to $27 \%$ among men $(\mathrm{M}=$ 36.79, $\mathrm{SD}=5.85)$.

Region Participant's responses to region were dummy-coded Costal (Guayas \& Manabí), Highland (Pichincha \& Santo Domingo), and Other as the reference group. Although these data weren't collected in ways to address our specific question of interest because the "Other" variable included Costal and Highland provinces, differences between mean anxiety scores due to province were statistically significant $(\mathrm{F}(2,290)=3.373, p=.033)$. Follow-up analyses indicated between group differences were statistically significant for Other and Costal Provinces $(\mathrm{M}=37.35, p=.009)$.

Variables for dependents and chronic illness were dummy coded with one dependent (Partner or none) as the reference group compared to more than one (children, children \& partner, parents, parents \& siblings, parents (repeated twice), children \& siblings, all of the above) and no chronic illness as the reference group. Although individuals with more than one dependent and a history of chronic illness reported greater anxiety, differences were not statistically significant $(d s=-0.29[-0.66,0.1] ;-0.15,[-0.44,0.14]$, respectively).

Table 1. Participant demographic characteristics as predictors of SAS levels during COVID

\begin{tabular}{|c|c|c|c|c|c|}
\hline Factor & $n(\%)$ & $\begin{array}{c}\text { SAS } \\
M(\mathbf{S D})\end{array}$ & $\begin{array}{c}\text { SAS > } 40 \\
n(\%)\end{array}$ & $\boldsymbol{R} 2$ & $p$ \\
\hline Gender & & & & .05 & $>.01$ \\
\hline Women & 212 & $40.1 a(6.4)$ & $92(44 \%)$ & & \\
\hline Men & 81 & $36.8 b(5.9)$ & $22(27 \%)$ & & \\
\hline Region & & & & .08 & .03 \\
\hline Other & 163 & $39.8 a(5.6)$ & $72(44 \%)$ & & \\
\hline Coastal & 61 & $37.4 a b(5.6)$ & $15(25 \%)$ & & \\
\hline Highlands & 69 & $39.1 b(6.4)$ & $27(39 \%)$ & & \\
\hline \multicolumn{6}{|l|}{ Dependents } \\
\hline Partner only & 31 & $37.5 a(6.2)$ & $8(26 \%)$ & & \\
\hline Multiple & 262 & $39.3 a(6.4)$ & $106(40 \%)$ & & \\
\hline \multicolumn{6}{|l|}{ Chronic Illness } \\
\hline No & 235 & $40 b(6.2)$ & $72(41 \%)$ & & \\
\hline Yes & 58 & $38.7 b(6.6)$ & $42(36 \%)$ & & \\
\hline
\end{tabular}

Note: Levels of a given predictor variable that don't share a subscript differ significantly $(p<.05)$. Statistical Relationships and Work-Related Factors

Profession Participants' professions were dummy coded as Physicians, Other (stretcher-bearer, ambulance chauffer, imaging testing radiologist, and lab technician), and Nursing/ Nursing Assistants as the reference group. Results of the multiple regression indicated differences between mean self-assessed anxiety scores due to profession were statistically significant $(\mathrm{F}(2,290)=3.373$, $\mathrm{p}=.036)$ as seen in Table 2. Follow-up analyses indicated between-group differences were statistically significant for Nursing/ Nursing Assistants and Other $(\mathrm{M}=36.96, \mathrm{p}=.018)$.

Professional Area Participants' professional areas were dummy coded as Inpatient, Urgency/ Emergency Care, and Outpatient as the reference group. Differences between mean anxiety scores due to professional area were marginally statistically significant $(\mathrm{R} 2=.019$, $\mathrm{F}(2,290)=2.805, \mathrm{p}=.06)$. Follow-up analyses indicated between-group differences were statistically significant for healthcare professionals working in Outpatient and in Urgency/ Emergency Care $(\mathrm{M}=40.39, \mathrm{p}=.0318)$.

Variables for years since graduation were dummy coded with less than 5 years since graduation as the reference group. Although individuals with less than 5 years since graduation reported greater anxiety, this difference was not statistically significant $(\mathrm{d}=0.14[-$ $0.11,0.40])$.

Table 2. Participant occupational characteristics as predictors of SAS levels during COVID

\begin{tabular}{cccccc}
\multicolumn{1}{c}{ Factor } & $\boldsymbol{n ( \% )}$ & $\begin{array}{c}\text { SAS } \\
\text { M(SD) }\end{array}$ & $\begin{array}{c}\text { SAS }>40 \\
\boldsymbol{n}(\%)\end{array}$ & $\boldsymbol{R 2}$ & $\boldsymbol{p}$ \\
Professional Area & & & & .086 & .21 \\
Outpatient & 148 & $38.6 a(6.3)$ & $57(61 \%)$ & & \\
Inpatient & 50 & $38.3 a b(5.9)$ & $16(32 \%)$ & &
\end{tabular}




\begin{tabular}{|c|c|c|c|c|c|}
\hline Emergency Care & 95 & $40.4 b(6.7)$ & $41(43 \%)$ & & \\
\hline Profession & & & & .91 & .46 \\
\hline Nursing & 108 & $40.2 a(6.5)$ & $56(52 \%)$ & & \\
\hline Doctor & 158 & $38.8 a b(6.4)$ & $53(34 \%)$ & & \\
\hline Other & 27 & $37 b(5)$ & $2(7 \%)$ & & \\
\hline $\begin{array}{ll}\text { Years } & \text { since } \\
\text { Graduation } & \end{array}$ & & & & & \\
\hline $1-5$ years & 92 & $39.8 a(5.3)$ & $40(43 \%)$ & & \\
\hline More than 5 & 201 & $38.86 a(6.8)$ & $74(37 \%)$ & & \\
\hline
\end{tabular}

Note: Levels of a given predictor variable that don't share a subscript differ significantly $(p<.05)$. Statistical Relationships and Structural Factors

Training about COVID Training was dummy coded with participants who receive no training about the COVID-19 emergency within the past week as the reference group. Anxiety among individuals who did not receive training on the health crisis was significantly higher than those who did $(\mathrm{d}=0.3[0.04,0.56])$, as seen in Table 3. Of those reporting no training about the crisis within the past week, $46 \%$ exceeded the clinical threshold for anxiety, compared to $36 \%$ of those who did receive training.

Practice Sector Sector was dummy coded with the IESS as the reference group. Results indicated differences between mean anxiety scores due to practice sectors were not statistically significant $(\mathrm{F}(2,290)=1.424, \mathrm{p}=.24)$ as seen in Table 3.

Other Structural Variables. Work contracts and mental health support in the workplace were dummy coded with individuals who had no permanent work contract nor mental health support in the workplace as reference groups. As seen in Table 3, differences in anxiety between individuals with and without a permanent work contract or mental health support in the workplace were not statistically significant $(\mathrm{d}=-0.03[-0.28,0.22]) ; \mathrm{d}=0.13[-0.11,0.36]$, respectively).

Table 3. Participant structural characteristics as predictors of SAS levels during COVID

\begin{tabular}{|c|c|c|c|c|c|}
\hline Factor & $n(\%)$ & $\begin{array}{c}\text { SAS } \\
M(S D)\end{array}$ & $\begin{array}{c}\text { SAS }>40 \\
n(\%)\end{array}$ & $R 2$ & $p$ \\
\hline COVID-19 Training & & & & .108 & .02 \\
\hline No & 79 & $40.5 a(6.5)$ & $36(46 \%)$ & & \\
\hline Yes & 214 & $38.6 b(6.3)$ & $78(36 \%)$ & & \\
\hline \multicolumn{6}{|l|}{ Practice Sector } \\
\hline Private & 32 & $37.6 a(6)$ & $9(28 \%)$ & & \\
\hline IESS & 212 & $39.2 a(6.4)$ & $82(39 \%)$ & & \\
\hline MSP & 49 & $40.1 a(6.4)$ & $23(47 \%)$ & & \\
\hline \multicolumn{6}{|l|}{ Work Contract } \\
\hline No & 202 & $39.9 a(6.5)$ & $40(44 \%)$ & & \\
\hline Yes & 91 & $38.1 a(6.2)$ & $74(36 \%)$ & & \\
\hline $\begin{array}{l}\text { Mental } \\
\text { Support }\end{array}$ & & & & & \\
\hline No & 176 & $39.5 b(6.3)$ & $72(41 \%)$ & & \\
\hline Yes & 117 & $38.7 b(6.6)$ & $42(36 \%)$ & & \\
\hline
\end{tabular}

Note: Levels of a given predictor variable that don't share a subscript differ significantly $(p<.05)$. Confounds of Significant and Marginally Significant Predictors

Researchers conducted a hierarchical regression analysis (Table 4) to control for possible confounding among the predictors that emerged as significant in Tables 1-3. At Steps 1 and 2, both gender and region of origin were demographic factors that contributed significantly to self-reported anxiety in the regression model $(\mathrm{F}(1,291)=15.99, \mathrm{p}=<.01$ and $\mathrm{F}(3,289)=7.89$, $\mathrm{p}=.026$, respectively), accounting for $5 \%$ and $7.5 \%$ of the variance as seen in Table 6 . At Steps 3 and 4 , the occupational factors of Professional Area and Profession did not remain significant to predicting self-reported anxiety in the regression model $(\mathrm{F}(5,287)=$ $5.38, \mathrm{p}=.21$ and $\mathrm{F}(7,285)=4.06, \mathrm{p}=.46$, respectively), but accounted for $8.6 \%$ and $9.1 \%$ of the variance, respectively. In the final regression model, the structural factor of receipt of COVID-19 Training and the demographic factors of gender and region remained significant predictors $(\mathrm{F}(8,284)=4.311, \mathrm{p}=.018)$, accounting for $10.8 \%$ of the variance of self-reported anxiety. 
Table 4 Summary of Hierarchical Regression Analysis for Significant variables predicting Anxiety

\begin{tabular}{|c|c|c|c|c|c|c|c|c|c|}
\hline \multirow[t]{2}{*}{ Factor } & \multicolumn{3}{|c|}{ On initial entry } & \multicolumn{3}{|c|}{ Final model } & \multirow[b]{2}{*}{$\mathbf{R 2}$} & \multirow[b]{2}{*}{$\Delta \mathbf{R} \mathbf{2}$} & \multirow[b]{2}{*}{$p$} \\
\hline & B & $95 \% \mathrm{CI}$ & $p$ & B & $95 \% \mathrm{CI}$ & $p$ & & & \\
\hline \multicolumn{10}{|l|}{ Demographic Factors } \\
\hline Step 1: Gender (Female) & & & & & & & .05 & & \\
\hline Male & -3.3 & {$[-4.85,-1.65]$} & 0 & -2.96 & {$[-4.66,1.26]$} & .001 & & & \\
\hline Step 2: Region (Other) & & & & & & & .075 & .024 & .03 \\
\hline Highlands & -.84 & {$[-2.58, .9]$} & .34 & -.79 & {$[-2.61,1.02]$} & .39 & & & \\
\hline Coast & -2.51 & {$[-4.33,-.69]$} & .01 & -2.35 & {$[-4.3,-.42]$} & .02 & & & \\
\hline \multicolumn{10}{|l|}{ Occupational Factors } \\
\hline $\begin{array}{l}\text { Step 3: Professional Area } \\
\text { (Outpatient) }\end{array}$ & & & & & & & .086 & .009 & .21 \\
\hline Inpatient & -.88 & {$[-3.0,1.24]$} & .41 & -1.54 & {$[-3.7, .63]$} & .16 & & & \\
\hline Emergency Care & 1.01 & {$[.86,-.68]$} & .24 & .79 & {$[-.91,2.48]$} & .36 & & & \\
\hline $\begin{array}{l}\text { Step 4: } \quad \text { Profession } \\
\text { (Nursing) }\end{array}$ & & & & & & & .091 & .005 & .46 \\
\hline Doctor & -.31 & {$[-1.94,1.31]$} & .7 & -.09 & {$[-1.71,1.53]$} & .92 & & & \\
\hline Other & -1.77 & {$[-4.6,1.04]$} & .2 & -1.38 & {$[-4.18,1.43]$} & .34 & & & \\
\hline \multicolumn{10}{|l|}{ Structural Factors } \\
\hline $\begin{array}{l}\text { Step 5: COVID Training } \\
\text { (No) }\end{array}$ & & & & & & & .108 & .018 & .02 \\
\hline Yes & & & & -1.99 & {$[-3.65,-.34]$} & .02 & & & \\
\hline
\end{tabular}

\section{Discussion}

The health impact of the COVID-19 pandemic on Ecuador must be situated within a broader historical context of structural violence (Vega Delgado 2017; Capella et al 2020). Structural violence renders visible histories of dominating oppressive systems and how such are endured by those marginalized by poverty and gender inequalities (Farmer, 2004). The COVID-19 Pandemic strains countries like Ecuador with limited health care infrastructure: a product of centuries of power asymmetries as well as present day sources of inequality and violence mainly affecting low-income, non-white ethnicities and gender-minorities (Capella et al 2020; Chiriboga et al. 2020). For example, only 8 of 24 provinces had authorized COVID-19 processing laboratories which may be contributing to critical delays in processing, low numbers of confirmed COIVD cases, and timely awareness critical to public health decision making (Torres \& Sacoto, 2020). Ecuadorian medical professionals have shown remarkable resilience in this broader context of health inequity during the global COVID-19 pandemic.

Results of this study suggest concerning levels of anxiety amongst Ecuadorian healthcare providers within a context of limited structural support during the COVID-19 pandemic. The overall mean sample score $(\mathrm{M}=39.14, S D=8.17)$ was just under the clinical anxiety threshold. Additionally, a majority $(63 \%, n=114)$ of the sample appeared to meet the clinical threshold for anxiety, highlighting the significant psychological toll of the COVID-19 crisis on health care workers. These findings exceed findings of recent meta-analyses suggesting a 30\% prevalence rate of anxiety amongst health care workers around the world (Marvaldi 2021). Unaddressed mental health problems of healthcare workers have been associated with decreased productivity and reduced quality of patient care (Tawfik et al. 2019, Pereira-Lima et al. 2019, as cited in Marvaldi 2021). Given the significant consequences, these findings should incentivize psychological interventions to address health care workers' psychological distress during the COVID-19 pandemic.

Although the occupational factors of Profession and Professional Area individually significantly predicted anxiety levels, they were no longer significant once accounting for other confounding variables. Specifically, our findings suggest nurses or nursing assistants as well as health care providers working in emergency care reported greater anxiety levels. Previous research indicates physicians are less psychologically affected than nurses during epidemic outbreaks (Preti et al. 2020) perhaps due to nurses having more physical contact with patients or less training (Preti et al 2020). Although our marginally significant occupational factors align with previous literature suggesting providers working at high-risk units to be at greater risk for psychological distress (Preti et al. 2020), our findings suggest other structural and demographic factors were stronger significant predictors of anxiety.

Receiving training about the COVID-19 pandemic within the past week was the only structural factor that significantly predicted lower levels of self-reported anxiety when accounting for other confounding factors. Although individuals who had no mental health support in the workplace, worked for the ministry of health, and had no permanent work contract reported greater levels of anxiety, these factors did not emerge as significant factors for mental health outcomes. These findings align with previous literature highlighting increasing knowledge about preventing and managing the COVID-19 disease can improve the morale and psychological 
well-being of front-line healthcare workers (Chirico et al., 2021). Specifically, timely and transparent updates on recent information have been previously associated with lower levels of anxiety and healthy psychological adaptation (Lasheras et al. 2020 as cited in Santabarbara et al. 2021).

Our results suggest gender and region could be sociodemographic protective factors to consider regarding self-reported anxiety levels during COVID times. Specifically, our findings suggest male healthcare workers were less likely to self-report anxiety than female health care workers. Previous findings of gender and its association with mental health outcomes during health-related pandemics has found mixed results (Preti et al 2020). Perhaps higher anxiety thresholds could be due to differences in gender-related work expectations such as spending greater time and effort in patient care (Huang et al. 2021). Mautong et al. 2021 reported Ecuadorian women during the COVID-19 pandemic reported significantly higher levels of depression, anxiety, and stress than men perhaps due to restrictions of schools and daycare center increasing caregiving roles and responsibilities in the household, increase rates of domestic violence during the pandemic, or higher risk of losing employment (Bradbury-Jones \& Isham 2020, Mautong et al. 2021). Additionally, due to design flaws we were not able to independently assess for regional effects on self-reporting anxiety. However, contrary to our hypotheses, our results indicated individuals in Costal provinces (Guayas and Manabí specifically) appeared to report lower anxiety levels relate to Other and Highland regions even when accounting for other confounding variables. These findings could suggest that Costal providers' anxiety levels could have been waning having already passed through the peak of the epidemic in April 2020 (Santabarbara et al. 2021). Although the literature suggests individuals without chronic illnesses or fewer dependents were at greater risk to report anxiety, in this study differences weren't statistically significant (Preti et al. 2020; Mautong et al. 2021).

\section{Limitations}

Findings of the present study could be limited due to sampling error in that health care providers who were most affected by the pandemic may have been more likely to respond to the survey. The psychometric properties of norm-references screeners such as the SAS have been associated with some confusion and disadvantages (Dunstan \& Scott 2020, 8-13). For example, confusion exists in the literature between employing SAS index and raw scores as cut-offs, with many instances of index score ranges being incorrectly applied (Dunstan \& Scott 2018). Although the scale remains a valuable, widely used screener for anxiety, future studies should ensure standardization and reliable interpretation of scores in comparable studies and in culturally similar populations. Additionally, future studies should further explore how the timing of training about the healthcare crises may relate to clinical levels of psychological distress.

\section{Recommendations \& Future Directions}

Ecuador has been one of the last countries in Latin America to establish National Mental Health Policies, a process which the Ecuadorian Ministry of Health began in 2012 (Ministerio de Salud Publica del Ecuador/ MSP 2014). To promote workplace wellness the first National policies of Workplace Health 2019-2025 were established in congruence with the Ecuadorian Constitution, the National Development Plan 2017-2021 "Toda una Vida" (Semplades 2017), the Family, Community, and Intercultural Model of integrated care (MAIS-FCI; Ministerio de Salud Pública del Ecuador 2012), and the United Nations 2030 Objectives of sustainable development (UN; 2015). Therefore, before the COVID-19 pandemic the Ecuadorian mental health care system was already in a liminal state- by slowly receiving greater state recognition(Capella et al 2020). Policies were implemented with the goal of proactive participation of employers in preventing, promoting, and quality integrated workplace wellness (MSP 2014). We recommend policies and institutions continue raising awareness of mental health concerns during the COVID-19 pandemic.

Prior to the pandemic, the IESS's most recent national data on workplace wellness report mental or psychological stress account for one third of indirect factors that harm workers, but don't report on the toll of psychological illnesses (IESS 2018). Given that symptoms of anxiety could be risk factors for chronic workplace illnesses affecting both the employee and patient care, it is imperative that health officials at the national level continue documenting and considering psychological distress in the development of specific workplace wellness policies and interventions.

In alignment with the ministry of health's published recommendations for workplace wellness, we recommend health care employers consider attending to the mental health needs of health service providers (MSP, 2019). Previous literature suggesting increasing availability of mental health support in the workplace could better equip healthcare workers to attend to COVID-related psychological distress (Balasubramanian et al. 2020). Employers should consider attending to geographic, training, and gender differences when designing and implementing strategies to attend to Ecuadorian health care providers' psychological wellbeing, especially given that $70 \%$ of the global health workforce are women (Organisation for Economic Co-Operation and Development 2021). Finally, we recommend employers provide sufficient staff training and resources to address the COVID-19 pandemic as prevention measures to improve their psychological well-being.

\section{Funding Source}

This research did not receive any specific grant from funding agencies in the public, commercial, or not-for-profit sectors.

\section{Declaration of Competing Interest}

Authors declare no conflict of interest. 


\section{Acknowledgements}

The author thanks Dr. Carlos Troya and Dr. Diego Herrera for the study conception and acquisition of the data. The author is grateful to the University of Wisconsin-Madison's Graduate Training Program in Mental Health Equity led by Dr. Mindi Thomspon who made the time and resources to conduct this research possible. The author also thanks Dr. William Hoyt and Emily Hamm (University of Wisconsin-Madison) for their informal help and critical contributions.

\section{References}

American Psychiatric Association. (1968). DSM-II: Diagnostic and statistical manual of mental disorders. https://doi.org/10.1176/appi.books.9780890425596

Álvarez, A. K. G., Almaguer, A. Y. C., Ramírez, G. R., López, A. M. M., Godales, T. de J. G., \& Ruiz, A. L. (2021). Capacitación en seguridad psicológica a la alta dirección hospitalaria en el afrontamiento a la COVID-19. Educación Médica Superior, 35(0), Article 0 . http://www.ems.sld.cu/index.php/ems/article/view/2735

Amnesty international (2020, July 30). Exposed, silenced, attacked: failures to protect health and essential workers during the covid19 pandemic (Policy Number: 40/2572/2020). Amnesty international ltd. Https://www.amnesty.org/download/documents/pol4025722020english.pdf.

Asmundson, G.J.G., Taylor, S., 2020. How health anxiety influences responses to viral outbreaks like COVID-19: what all decisionmakers, health authorities, and health care professionals need to know. J. Anxiety Disord. 71, 102211. https://doi.org/ 10.1016/j.janxdis.2020.102211.

Balasubramanian, A., Paleri, V., Bennett, R., \& Paleri, V. (2020). Impact of COVID-19 on the mental health of surgeons and coping strategies. Head \& Neck, 42(7), 1638-1644. https://doi.org/10.1002/hed.26291

Bradbury-Jones C, Isham L. The pandemic paradox: The consequences of COVID-19 on domestic violence. J Clin Nurs. 2020;29(1314):2047-9. https:// doi.org/10.1111/jocn.15296.

Capella Palacios, M., \& Jadhav, S. (2020). How coloniality shapes the making of Latin American psychologists: Ethnographic evidence from Ecuador. International Review of Psychiatry, 32(4), 348-358. https://doi.org/10.1080/09540261.2020.1761777

Chirico, F., Nucera, G., \& Magnavita, N. (2021). Protecting the mental health of healthcare workers during the COVID-19 emergency. BJPsych International, 18(1), E1. https://doi.org/10.1192/bji.2020.39

Chiriboga, D., Garay, J., Buss, P., Madrigal, R. S., \& Rispel, L. C. (2020). Health inequity during the COVID-19 pandemic: A cry for ethical global leadership. The Lancet, 395(10238), 1690-1691. https://doi.org/10.1016/S0140-6736(20) $\underline{31145-4}$

Dunstan, D. A., \& Scott, N. (2018). Assigning clinical significance and symptom severity using the Zung scales: Levels of misclassification arising from confusion between index and raw scores. Depression Research and Treatment, 2018. https://doi.org/10.1155/2018/9250972

Dunstan, D. A., \& Scott, N. (2020). Norms for Zung's Self-rating Anxiety Scale. BMC Psychiatry, $20(1)$, 90. https://doi.org/10.1186/s12888-019-2427-6

El Comercio. El 43,8\% de contagiados es personal médico, según Salud. (2020, November 30). El Comercio. https://www.elcomercio.com/actualidad/contagios-medicos-personal-salud-covid19.html

Farmer, P. (2004). An Anthropology of Structural Violence. Current Anthropology (45), 3. https://www-journals-uchicagoedu.ezproxy.library.wisc.edu/doi/pdf/10.1086/382250

France 24. (2020, September 5). Médicos de Ecuador afirman "sentirse desprotegidos" frente a la pandemia. https://www.france24.com/es/20200905-ecuador-renuncia-masiva-profesionales-salud

García-Iglesias, J. J., Gómez-Salgado, J., Martin-Pereira, J., Fagundo-Rivera, J., Ayuso-Murillo, D., Riera-Martínez, J., R., RuizFrutos, C. (2020). Impacto del SARS-COV-2 (COVID-19) en la salud mental de los profesionales sanitarios: una revision sistemática. Revista Española Salud Pública, (93), 1-20, e202007088.

Herrera, D., Troya Altamirano, C., \& Gaus, D. (2021). COVID-19 in Ecuador: Imported Control Strategies without Context in a Challenged Healthcare System. The American Journal of Tropical Medicine and Hygiene, 104(2), 414-415. https://doi.org/10.4269/ajtmh.20-1347

Huang, L., Lei, W., Xu, F., Liu, H., \& Yu, L. (2020). Emotional responses and coping strategies in nurses and nursing students during Covid-19 outbreak: A comparative study. PLOS ONE, 15(8), e0237303. https://doi.org/10.1371/journal.pone.0237303

Instituto Ecuatoriano de Seguridad Social (2018, November). Seguro General de Riesgos de Trabajo: Boletín Estadístico.https://www.iess.gob.ec/documents/10162/51889/Boletin_estadistico_2018_nov_dic.pdf

Lasheras, I., Gracia-García, P., Lipnicki, D.M., Bueno-Notivol, J., Lo pez-Anto ’́n, R., De Là Camara, C., Lobo, A., Santab'arbara, J., 2020. Prevalence of anxiety in medical students during the COVID-19 pandemic: a rapid systematic review with meta- analysis. Int. J. Environ. Res. Public Health 12 (18), 1-12. https://doi.org/10.3390/ ijerph17186603.

Lasluisa Alban, S. F., \& Llumitasig Guanoquiza, E. M. (2019). Prevalencia de trastornos ansiosos y depresivos en los estudiantes de la Carrera de Enfermería de la Universidad Central del Ecuador, en el periodo octubre 2018 - septiembre 2019. http://www.dspace.uce.edu.ec/handle/25000/19658

Marvaldi, M., Mallet, J., Dubertret, C., Moro, M. R., \& Guessoum, S. B. (2021). Anxiety, depression, trauma-related, and sleep disorders among healthcare workers during the COVID-19 pandemic: A systematic review and meta-analysis. Neuroscience \& Biobehavioral Reviews, 126, 252-264. https://doi.org/10.1016/j.neubiorev.2021.03.024

Mautong, H., Gallardo-Rumbea, J. A., Alvarado-Villa, G. E., Fernández-Cadena, J. C., Andrade-Molina, D., Orellana-Román, C. E., \& Cherrez-Ojeda, I. (2021). Assessment of depression, anxiety and stress levels in the Ecuadorian general population during social isolation due to the COVID-19 outbreak: A cross-sectional study. BMC Psychiatry, 21(1), 212. https://doi.org/10.1186/s12888-02103214-1 
Ministerio de Salud Pública del Ecuador. (2012). Modelo de Atención Integral del Sistema Nacional de Salud.https://www.kimirina.org/images/kimirina/documentos/publicaciones/Manual Modelo Atencion Integral Salud Ecuador 2012Logrado-ver-amarillo.pdf

Ministerio de Salud Pública del Ecuador. (2014, February). Politica Nacional de Salud Mental $2014-2024$. http://www.confbasaglia.org/wp-content/uploads/2019/01/legislazioni-ecuador-2014-2024.pdf.

Medina, K., Morán, S., Ponce, P. (2021, March 10). Ecuador desentierra cuerpos para encubrir sus culpas. Periodismo de Investigación de las Americas. Retrieved March 20, 2021, from https://www.desentierroscovid.ec/

Navarro, J.-C., Arrivillaga-Henríquez, J., Salazar-Loor, J., \& Rodriguez-Morales, A. J. (2020). COVID-19 and dengue, co-epidemics in Ecuador and other countries in Latin America: Pushing strained health care systems over the edge. Travel Medicine and Infectious Disease, 37, 101656. https://doi.org/10.1016/j.tmaid.2020.101656

Orellana, C.I., Orellana, L.M., 2020. Predictores de síntomas emocionales durante la cuarentena domiciliar por pandemia de COVID19 en El Salvador. Actual. En Psicol. 34, 103-120. https://doi.org/10.15517/ap.v34i128.41431

Organisation for Economic Co-Operation and Development (2020). OECD: Policy Responses to Coronavirus: Women at the core of the fight against COVID-19 crisis. file://Users/gabriellalgaus/Zotero/storage/NJRYAZUT/women-at-the-core-of-the-fight-againstcovid-19-crisis-553a8269.html

Paulino, M., Dumas-Diniz, R., Brissos, S., Brites, R., Alho, L., Simõ es, M.R., Silva, C.F., 2020. COVID-19 in Portugal: exploring the immediate psychological impact on the general population. Psychol. Health Med. https://doi.org/10.1080/ 13548506.2020.1808236.

Pereira-Lima, Karina, Mata, Douglas A., Loureiro, Sonia R., Crippa, José A., Bolsoni, L.ívia M., Sen, Srijan, (2019). Association between physician depressive symptoms and medical errors: a systematic review and meta-analysis. JAMA Network Open 2 (11), e1916097.

Preti, E., Di Mattei, V., Perego, G., Ferrari, F., Mazzetti, M., Taranto, P., Di Pierro, R., Madeddu, F., \& Calati, R. (2020). The Psychological Impact of Epidemic and Pandemic Outbreaks on Healthcare Workers: Rapid Review of the Evidence. Current Psychiatry Reports, 22(8), 43. https://doi.org/10.1007/s11920-020-01166-z

R Core Team (2021). R: A language and environment for statistical computing. R Foundation for

Statistical Computing, Vienna, Austria. URL https://www.R-project.org/.

Sahebi, A., Nejati-Zarnaqi, B., Moayedi, S., Yousefi, K., Torres, M., \& Golitaleb, M. (2021).The prevalence of anxiety and depression among healthcare workers during the COVID-19 pandemic: An umbrella review of meta-analyses. Progress in NeuroPsychopharmacology and Biological Psychiatry, 107, 110247. https://doi.org/10.1016/j.pnpbp.2021.110247.

Santabárbara, J., Lasheras, I., Lipnicki, D. M., Bueno-Notivol, J., Pérez-Moreno, M., López-Antón, R., De la Cámara, C., Lobo, A., \& Gracia-García, P. (2021). Prevalence of anxiety in the COVID-19 pandemic: An updated meta-analysis of community-based studies. Progress in Neuro-Psychopharmacology and Biological Psychiatry, 109, 110207. https://doi.org/10.1016/j.pnpbp.2020.110207

Secretaria Nacional de Planificación y Desarollo, Semplades (2017). Toda una Vida: Plan Nacional de Desarrollo $2017-2021$. https://www.planificacion.gob.ec/wp-content/uploads/downloads/2017/10/PNBV-26-OCT-FINAL_0K.compressed1.pdf

Spoorthy, M. S., Pratapa, S. K., \& Mahant, S. (2020). Mental health problems faced by healthcare workers due to the COVID-19 pandemic-A review. Asian Journal of Psychiatry, 51, 102119. https://doi.org/10.1016/j.ajp.2020.102119

Tusev, A., Tonon Ordóñez, L., \& Capella, M. (2020). The Initial Mental Health Effects of the Covid-19 Pandemic Across Some Ecuadorian Provinces. 15, 11-24. https://doi.org/10.31095/investigatio.2020.15.2

Tawfik, Daniel S., Scheid, Annette, Profit, Jochen, Shanafelt, Tait, Trockel, Mickey, Adair, Kathryn C., Bryan Sexton, J., Ioannidis, John P.A. (2019). Evidence relating health care provider burnout and quality of care: a systematic review and meta- analysis. Ann. Intern. Med. $171(8), 555-567$.

Torres, I., \& Sacoto, F. (2020). Localising an asset-based COVID-19 response in Ecuador. The Lancet, 395(10233), 1339. https://doi.org/10.1016/S0140-6736(20) $\underline{30851-5}$

Vega Delgado, G. (2017). Locos intelectuales y locos de la vida cotidiana en el Ecuador. Siglos XVII al XX. La Mirada de una psiquiatria sobre la historia [Unpublished doctoral dissertation]. Programa de doctorado en historia de America Latina: Universidad Pablo de Olivade.

Vinueza-Veloz, A. F., Aldaz-Pachacama, N. R., Mera-Segovia, C. M., Pino-Vaca, D. P., Tapia-Veloz, E. C., \& Vinueza-Veloz, M. F. (2020). Síndrome de Burnout en médicos/as y enfermeros/as ecuatorianos durante la pandemia de COVID-19. https://doi.org/10.1590/SciELOPreprints. 708

United Nations (2015). Transforming our world: The 2030 Agenda for Sustainable Development | Department of Economic and Social Affairs. Retrieved March 25, 2021, from https://sdgs.un.org/2030agenda

World Health Organization (2020, March 11). WHO Director-General's opening remarks at the media briefing on COVID-19-11 March 2020. Retrieved June 27, 2021, from https://www.who.int/director-general/speeches/detail/who-director-general-s-openingremarks-at-the-media-briefing-on-covid-19---11-march-2020

Zung, W. W. K. (1971). A Rating Instrument For Anxiety Disorders. Psychosomatics, 12(6), 371-379. https://doi.org/10.1016/S0033$\underline{3182}(\underline{71}) \underline{71479-0}$ 